\title{
Interval-Valued Neutrosophic Sets to Develop Multi-Criteria Decision Making Approach for Renewable Energy Selection
}

\author{
Shuo-Yan CHOU, Xuan-Loc PHAM and Thi Anh Tuyet NGUYEN ${ }^{1}$ \\ Department of Industrial Management, National Taiwan University of Science and \\ Technology, No 43 Section 4, Keelung Rd., Taipei 10607, Taiwan, ROC
}

\begin{abstract}
Due to lack of indigenous conventional energy resources, renewable energy has become a potential alternative for Taiwan's future energy supply. Numerous studies have recently emerged on renewable issues in Taiwan. However, studies that specifically consider effects of various influential parameters on evaluation and selection of renewable energy sources based on multi-criteria decision making (MCDM) approach under neutrosophic environment are still limited to some specific part of the renewable energy sources (RES). MCDM methods has become increasingly popular in solving the decision-making problems which involve multiple criteria. This study proposes an extension of MCDM approach to evaluate renewable energy sources, using the combination of Analytic Hierarchy Process (AHP) technique with the Technique for Order of Preference by Similarity to Ideal Solution (TOPSIS) method based on interval - valued neutrosophic sets.
\end{abstract}

Keywords. MCDM Approach, Renewable Energy Sources, Neutrosophic Sets, AHP Method, TOPSIS Method.

\section{Introduction}

Energy plays an important role in the economic development, especially after energy crisis in 1970s [1]. Due to the characteristics of cleanliness to environment and inexhaustible nature, development of renewable energy is an important issue for many countries to address sustainable energy supply and overcome the anthropogenic negative impacts on the environment of fossil fuels $[2,3]$.

Taiwan, which is located in a low-latitude zone with outstanding benefits of the potential wind capacity, renewable energy sources (RES) have become more attractive to be developed [3]. Despite the enormous RES, the usage of renewable energy still remains a small portion. One of the key factors for this limitation is the high investment cost and the low return on investment compared to the conventional energy $[2,3]$. Therefore, it is necessary to consider thoroughly the impact of many factors such as financial, economic, political to technical perspective, to the evaluation and selection of the most appropriate RES [4]. Multi-criteria decision making (MCDM) approach has become popular in the field of energy planning due to the flexibility it provides to the

\footnotetext{
${ }^{1}$ Corresponding Author, Department of Industrial Management, National Taiwan University of Science and Technology, No 43 Section 4, Keelung Rd., Taipei 10607, Taiwan, ROC; Email: anhtuyet213@gmail.com
} 
decision makers to pay attention to all the criteria and make appropriate decisions with conflicting and multiple criteria [4, 5]. Five RES, namely Hydropower, Solar power, Wind power, Biomass power and Geothermal power, are being considered as alternatives in this paper.

The combination of MCDM techniques and fuzzy set theory, named as fuzzy MCDM, has been widely accepted and has been the most commonly approach in RES selection field [3]. However, fuzzy set can only handle incomplete information not the indeterminate information and inconsistent information and the indeterminacy will be by default [6-12]. In practice, the information for decision is often incomplete, indeterminate and inconsistent information [9] so using MCDM techniques and fuzzy sets cannot be absolutely effective. To cope with this disadvantage of fuzzy set, Smarandache [13] further proposed the neutrosophic set by adding an independent indeterminacy membership on the basis of fuzzy set [9].

Recently, neutrosophic sets has been becoming an interesting research topic and attracted widely attentions [7-9, 11, 12]. The combination of neutrosophic sets and MCDM approach has been successfully applied in different fields to solve problems as low-carbon supplier selection [14], supplier selection [15], evaluation of e-commerce websites [16], outsourcing provider selection [17], but in energy source selection field, it is still a blank area.

Moreover, the degree of truth, falsity and indeterminacy about a certain statement could not be defined precisely in real situations, so Wang [18] proposed an interval valued neutrosophic sets to overcome this difficulty. In this study, an extension of MCDM approach using interval - valued neutrosophic sets is proposed to evaluate RES in Taiwan. Under neutrosophic environment and AHP process, the weights of criteria are assessed in linguistic terms represented by interval - valued neutrosophic numbers. Then, these values are averaged into a comparable scale. Next, the weighted ratings of alternatives are also derived by interval - valued neutrosophic numbers. Finally, by employing TOPSIS technique, through the relative closeness coefficient, alternatives will be evaluated and ranked.

\section{Literature review}

The combination of MCDM models with fuzzy theory has been extensively used in ranking renewable energy alternatives, which has got a series of achievements. For instance, C. Kahraman and İ. Kaya [19] employed applied AHP method under fuzziness environment (FAHP) to select the best energy policy for Turkey from four perspectives (Technology, Environment, Socio - Political, Economic) and 17 subcriteria. At the end, wind energy was determined as the best energy policy alternative for in Turkey. Similarly, A. Tasri and A. Susilawati [20] based on a FAHP method to determine the best renewable energy sources for electricity generation for inIndonesia. Finally, with the highest final score, the hydro power was found to be the best energy source for this country, followed by geothermal, solar, wind energy and biomass. T. Kaya, C. Kahraman and J.R. San Cristóbal [19, 21-23] combined AHP method and VIKOR method to determine the best renewable energy alternative for Istanbul City and Spanish. A. Yazdani - Chamzini et al [24] used an integrated AHP process and COPRAS method including VIKOR, SAW, TOPSIS, ARAS and MOORA to select the best renewable energy project. They compared the model with these five MCDM tools to validate the output of the proposed model. 
Also, Y. Wu, C. Xu, T. Zhang [4] presented a FAHP model which based on the cumulative prospect theory to help public investors in choosing the most appropriate RES. With 14 subcriteria from economical, environmental, socio-political and technical aspect, solar PV was selected the best RES for China and the economical aspect was the criteria having the highest one. And M. Çolak, İ. Kaya [25] employed the AHP method using interval type-2 fuzzy sets and hesitant fuzzy TOPSIS methods to evaluate renewable energy alternatives for Turkey. The results showed that the criterion "Economic" was determined as the most important criterion among main criteria with the highest weight, and the wind energy was determined as the best renewable energy alternative for Turkey with the best relative closeness value.

After being proposed in 1999, neutrosophic sets has have been applied in many field since 2013, one of which is decision making process, namely neutrosophic MCDM approach [7]. From literature, AHP and TOPSIS are two of the most commonly used in MCDM process, but the combination of AHP method and TOPSIS technique under neutrosophic environment is still a blank area[25].

Recently, there have only had only has some studies proposing the model that used one of these two methods with neutrosophic sets. For instance, J. Ye [26] suggested entropy and similarity measures of single valued neutrosophic set and interval - valued neutrosophic set, respectively. Similarly, Z.-p. Tian [10] also developed the MCDM approach based on a cross entropy with interval - valued neutrosophic sets and examined its characteristics with the example of an investment appraised project. J. Ye [11] also proposed methods for solving MCDM problems using a cross-entropy and correlation coefficient. Or Pingping Chi [9] proposed a novel concept about TOPSIS method for the multiple attribute decision making problems in which the attribute weights were unknown and attribute values were expressed in the form of Interval - valued neutrosophic sets.

Besides, there are three neutrosophic AHP papers published by [7, 15, 27]. Radwan et al., [27] developed a novel hybrid neutrosophic AHP method in learning management systems. M. Abdel-Basset et al., [15] developed the integration of AHP into Delphi framework under neutrosophic environment and proposed a new technique for checking consistency and calculating consensus degree of expert's opinions. Meanwhile, E. Bolturk and C. Kahraman [7] presented two methods which are AHP alone and AHP with cosine similarity measure under interval neutrosophic environment.

Therefore, in this paper, an extension of MCDM approach using the combination of AHP and TOPSIS method under interval - valued neutrosophic sets is proposed for evaluating the most appropriate RES in Taiwan. This case study in Taiwan is carried out to illustrate the rationality and feasibility of the proposed method.

\section{Methodology}

\subsection{Evaluation criteria system}

Criteria and subcriteria system are the factors playing an important role in the RES selection decision-making process. In this paper, four main criteria were selected to analyze: Technical, Economical, Environmental and Socio - Politics aspect. Subcriteria associated with each criterion were also identified from literature and expert's opinion. Figure 1 is the evaluation criteria system of this paper. 


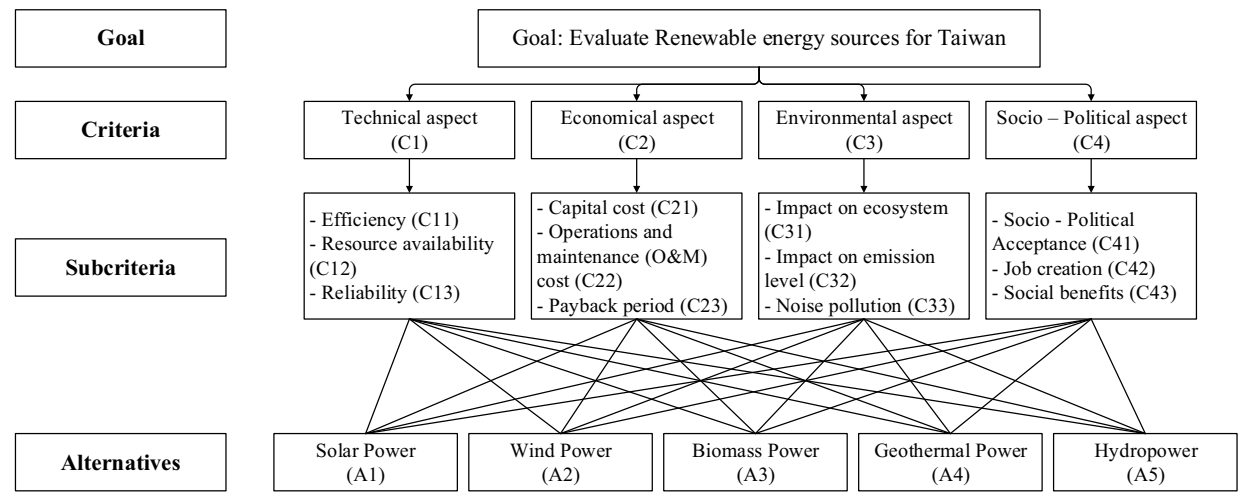

Figure 1. The evaluation criteria system of RES.

These subcriteria can be briefly summarized as follow:

- C11: Efficiency: This criterion is used to explain how much useful energy extracted from an energy source.

- C12: Resource availability: This criterion measures the availability of renewable energy resources to generate energy.

- C13: Reliability: This criterion indicates the ability of a system to operate within designed conditions.

- C21: Capital cost: This criterion refers to the total cost in establishing a power plant, includes the equipment, labor, installation cost, ...

- C22: Operation and maintenance cost (O\&M cost): This criterion includes two components: Operation costs, including salaries additional to the expenditure on energy production and services and maintenance costs are the funds spent to ensure reliable plant operations and to avoid failure and damage.

- C23: Payback period: This criterion is the period of time that is necessary to compensate the original cost of renewable energy plant.

- C31: Impact on ecosystem: This criterion is used to measure the disturbance of power plant on ecosystem.

- C32: Impact on emission level: This criterion refers to the impact of a power plant on the environment and society in terms of emission reduction.

- C33: Noise pollution: This is the criterion which indicates the impact of noise from a power plant on the environment.

- C41: Socio - Political Acceptance: This criterion reflects the consensus among government and other social partners for the proposed power plant.

- C42: Job creation: This criterion evaluates how many people the power projects can employ in their cycle life, from construction to decommissioning.

- C43: Social benefits: this criterion represents the social progress in the local community and region by initiating a power project.

\subsection{Neutrosophic sets and interval - valued neutrosophic sets}

Neutrosophic sets is a powerful general formal framework which generalizes the concepts of classic set, fuzzy set, interval-valued fuzzy set, intuitionistic fuzzy set, etc [11]. Based on fuzzy sets, F. Smarandache [13] added indeterminacy membership 
function in neutrosophic set, with the truth membership function and falsity membership function of intuitionistic fuzzy sets to handle incomplete, indeterminate and inconsistent information in real life [9].

Definition 1. Pingping Chi [9] Let $\mathrm{X}$ be a universe of discourse, with a generic element in $\mathrm{X}$ denoted by $x$. A neutrosophic set (NS) $\mathrm{A}$ in $\mathrm{X}$ is $A(x)=\left(T_{A}(x)\right.$, $\left.I_{A}(x), F_{A}(x)\right)$ where $T_{A}(x), I_{A}(x), F_{A}(x)$ are respectively the truth-membership function, indeterminacy-membership function, and the falsity-membership function. $T_{A}(x)$, $I_{A}(x), F_{A}(x)$ are real standard or nonstandard subsets of $] 0^{-}, 1^{+}[$.

There is no restriction on the sum of $T_{A}(x), I_{A}(x)$ and $F_{x}(x)$ so $0^{-} \leq T_{A}(x)+I_{A}(x)$ $+F_{A}(\mathrm{x}) \leq 3^{+}$.

Then, Wang [18] proposed Interval - Valued Neutrosophic Sets which can express three of membership functions in interval numbers, instead of crisp numbers.

Definition 2. Wang [18] Let $\mathrm{X}$ be a universe of discourse, with a generic element in $\mathrm{X}$ denoted by $x$. A neutrosophic set $\mathrm{A}$ in $\mathrm{X}$ is $A=\left\{x\left(T_{A}(x), I_{A}(x), F_{A}(x)\right) \mid x \in X\right\}$ where $T_{A}(x), I_{A}(x), F_{A}(x)$ are respectively the truth-membership function, indeterminacymembership function, and the falsity-membership function. For each point $x$ in $\mathrm{X}$, we have that $T_{A}(x)=\left[\inf T_{A}(x)\right.$, sub $\left.T_{A}(x)\right], I_{A}(x)=\left[\inf I_{A}(x), \operatorname{sub} I_{A}(x)\right], F_{A}(x)=$ $\left.\left[\inf F_{A}(x), \operatorname{sub} F_{A}(x)\right] \subseteq\right] 0^{-}, 1^{+}[$.

There is no restriction on the sum of $T_{A}(x), I_{A}(x), F_{A}(x)$ so $0^{-} \leq \operatorname{subT}_{A}(x)$ $+\operatorname{subI}_{A}(x)+\operatorname{subF}_{A}(x) \leq 3^{+}$.

For convenience, we can use $x=\left(\left[T^{L}, T^{U}\right],\left[I^{L}, I^{U}\right],\left[F^{L}, F^{U}\right]\right)$ to represent a value in Interval - Valued Neutrosophic Sets [9].

The Operational Rules of the Interval - Valued Neutrosophic Sets:

Let $x$ and $y$ are two Interval - Valued Neutrosophic Numbers, in which

$$
\begin{aligned}
& x=\left(\left[T_{1}^{L}, T_{1}^{U}\right],\left[I_{1}^{L}, I_{1}^{U}\right],\left[F_{1}^{L}, F_{1}^{U}\right]\right), \mathrm{y}=\left(\left[T_{2}^{L}, T_{2}^{U}\right],\left[I_{2}^{L}, I_{2}^{U}\right],\left[F_{2}^{L}, F_{2}^{U}\right]\right) \\
& x \oplus y=\left(\left[T_{1}^{L}+T_{2}^{L}-T_{1}^{L} \times T_{2}^{L}, T_{1}^{U}+T_{2}^{U}-T_{1}^{U} \times T_{2}^{U}\right],\right. \\
& {\left.\left[I_{1}^{L} \times I_{2}^{L}, I_{1}^{U} \times I_{2}^{U}\right],\left[F_{1}^{L} \times F_{2}^{L}, F_{1}^{U} \times F_{2}^{U}\right]\right) } \\
& x \otimes y=\left(\left[T_{1}^{L} \times T_{2}^{L}, T_{1}^{U} \times T_{2}^{U}\right],\left[I_{1}^{L}+I_{2}^{L}-I_{1}^{L} \times I_{2}^{L}, I_{1}^{U}+I_{2}^{U}-I_{1}^{U} \times I_{2}^{U}\right]\right. \\
& {\left.\left[F_{1}^{L}+F_{2}^{L}-F_{1}^{L} \times F_{2}^{L}, F_{1}^{U}+F_{2}^{U}-F_{1}^{U} \times F_{2}^{U}\right]\right) } \\
& n x=\left(\left[1-\left(1-T_{1}^{L}\right)^{n}, 1-\left(1-T_{1}^{U}\right)^{n}\right],\left[\left(I_{1}^{L}\right)^{n},\left(I_{1}^{L}\right)^{n}\right],\left[\left(F_{1}^{L}\right)^{n},\left(F_{1}^{L}\right)^{n}\right]\right) \\
&(\mathrm{n} \succ 0)
\end{aligned}
$$




\section{MCDM approach}

For evaluating renewable energy sources in Taiwan, an extension of MCDM approach using the combination of AHP and TOPSIS technique under neutrosophic environment will be proposed as in Figure 2. In the first step, an expert team is formed with three experts in energy sector.

Table 1: Linguistic terms and neutrosophicated strong weights

\begin{tabular}{cc}
\hline Linguistic term & Neutrosophic sets \\
\hline Absolutely Strong & {$[1,1],[0,0],[0,0]$} \\
Very Strong & {$[0.75,0.85],[0.1,0.2],[0.15,0.25]$} \\
Fairly Strong & {$[0.55,0.75],[0.2,0.4],[0.25,0.45]$} \\
Exactly Equal & {$[0.5,0.5],[0.5,0.5],[0.5,0.5]$} \\
Absolutely Weak & {$[0,0],[0,0],[1,1]$} \\
Very weak & {$[0.15,0.25],[0.1,0.2],[0.75,0.85]$} \\
Fairly weak & {$[0.25,0.45],[0.2,0.4],[0.55,0.75]$} \\
\hline
\end{tabular}

After selecting the alternatives and the most appropriate criteria and subcriteria from references and expert's opinions, the weights for decision criteria can be calculated. From the literature, this step may be obtained by a variety of techniques, one of which is the AHP method. It constructs pair-wise comparisons for a set of criteria to judge the relative importance of one criteria to another or one subcriteria to the others from the judgments of three experts through linguistic terms given in Table 1. In this paper, the AHP method the using interval - valued neutrosophic numbers concept adapted from [7].

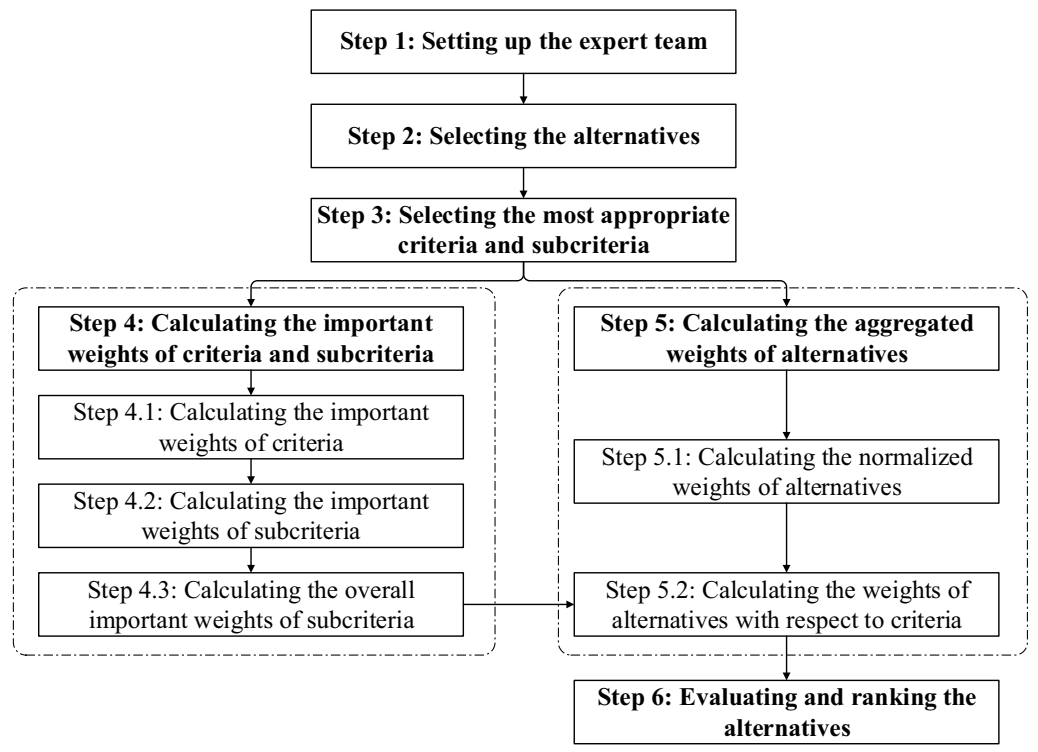

Figure 2. Decision framework of renewable energy evaluation

Then three equations Eq. (1), (2), (3) in the operations of Interval - Valued Neutrosophic Sets will be used to calculate the value of alternatives. Finally, TOPSIS method can evaluate and ranking the alternatives through the final value of alternatives. TOPSIS is one of the most common MCDM techniques, which was initially developed by Hwang and Yoon [1]. This technique evaluates alternatives according to their distance values to ideal solution (Positive Ideal Solution - PIS and Negative Ideal Solution - NIS) and relative closeness coefficient of each alternative. 
The basic principle of TOPSIS technique is that the best alternative should have the shortest distance to the positive ideal solution and the farthest distance to the negative ideal solution[9]. So, the smaller relative closeness coefficient $\left(\mathrm{RCC}_{\mathrm{i}}\right)$ is, the better alternative $A_{i}$ is. In this context, the positive ideal solution and negative ideal solution will be defined by the [9] and all of the equation to calculate in this step are also derived from research literature.

\section{Results}

In this section, the proposed neutrosophic MCDM approach will be applied to solve renewable energy sources evaluation problem.

Firstly, the weights of criteria are obtained by evaluations of three experts who have experience in energy decision making problems. As a result of expert evaluations, the pairwise comparison matrices of criteria and subcriteria are obtained and this paper applies the AHP method under neutrosophic environment (NAHP) of [7] to calculate the weights of criteria and subcriteria, which is given in Table 2.

Table 2. The weights of criteria and subcriteria

\begin{tabular}{|c|c|c|c|}
\hline \multicolumn{2}{|r|}{ Criteria weight } & \multicolumn{2}{|r|}{ Subcriteria weight } \\
\hline \multirow{3}{*}{$\mathrm{C} 1$} & & $\mathrm{C} 11$ & {$[0.531,0.531],[0.333,0.333],[0.071,0.071]$} \\
\hline & {$[0.381,0.398],[0.199,0.232],[0.057,0.070]$} & $\mathrm{C} 12$ & {$[0.175,0.223],[0.259,0.333],[0.381,0.454]$} \\
\hline & & $\mathrm{C} 13$ & {$[0.180,0.245],[0.259,0.333],[0.403,0.475]$} \\
\hline \multirow{3}{*}{$\mathrm{C} 2$} & & $\mathrm{C} 21$ & {$[0.206,0.275],[0.259,0.333],[0.337,0.420]$} \\
\hline & {$[0.263,0.303],[0.209,0.287],[0.153,0.198]$} & $\mathrm{C} 22$ & {$[0.140,0.190],[0.259,0.333],[0.451,0.509]$} \\
\hline & & $\mathrm{C} 23$ & {$[0.535,0.535],[0.333,0.333],[0.071,0.071]$} \\
\hline \multirow{3}{*}{$\mathrm{C} 3$} & & $\mathrm{C} 31$ & {$[0.249,0.325],[0.252,0.350],[0.273,0.343]$} \\
\hline & {$[0.165,0.198],[0.250,0.250],[0.226,0.243]$} & $\mathrm{C} 32$ & {$[0.206,0.272],[0.245,0.328],[0.335,0.389]$} \\
\hline & & $\mathrm{C} 33$ & {$[0.338,0.403],[0.229,0.322],[0.187,0.268]$} \\
\hline \multirow{3}{*}{$\mathrm{C} 4$} & & $\mathrm{C} 41$ & {$[0.252,0.336],[0.244,0.360],[0.253,0.339]$} \\
\hline & {$[0.075,0.101],[0.205,0.231],[0.470,0.490]$} & $\mathrm{C} 42$ & {$[0.351,0.410],[0.232,0.320],[0.177,0.250]$} \\
\hline & & $\mathrm{C} 43$ & {$[0.178,0.253],[0.232,0.320],[0.350,0.412]$} \\
\hline
\end{tabular}

From the weights of criteia and subcriteria, the overall weights of subcriteria is obtained from interval neutrosophic evaluation scale method proposed in [7]. The overall weight of subcriteria is shown in Table 3.

Table 3. The overall weights of subcriteria

\begin{tabular}{ccc}
\hline C11 & {$[0.202,0.212],[0.466,0.488],[0.124,0.136]$} \\
C12 & {$[0.067,0.089],[0.407,0.488],[0.417,0.492]$} \\
C13 & {$[0.069,0.098],[0.407,0.488],[0.437,0.512]$} \\
C21 & {$[0.054,0.083],[0.414,0.524],[0.439,0.534]$} \\
Overall Weight $=$ CW x SCW & C22 & {$[0.037,0.058],[0.414,0.524],[0.535,0.606]$} \\
C31 & {$[0.141,0.162],[0.473,0.524],[0.213,0.254]$} \\
C32 & {$[0.041,0.064],[0.439,0.512],[0.437,0.503]$} \\
C33 & {$[0.056,0.080],[0.422,0.491],[0.370,0.446]$} \\
C41 & {$[0.019,0.034],[0.399,0.508],[0.604,0.385]$} \\
C42 & {$[0.026,0.042],[0.390,0.477],[0.564,0.302]$} \\
C43 & {$[0.013,0.026],[0.390,0.477],[0.655,0.453]$} \\
\hline
\end{tabular}

And then, with the judgments of three experts and overall weights of subcriteria, Eq. (1), (2), (3) are used to calculate the final value of five alternatives that is presented in Table 4. 
Table 4. Final value of alternatives.

\begin{tabular}{cc}
\hline Alternatives & Final value \\
\hline Solar power (A1) & {$[0.039,0.060],[0.620,0.724],[0.555,0.613]$} \\
Wind power (A2) & {$[0.036,0.055],[0.656,0.754],[0.596,0.657]$} \\
Biomass power (A3) & {$[0.035,0.054],[0.664,0.761],[0.604,0.659]$} \\
Geothermal power (A4) & {$[0.033,0.052],[0.681,0.774],[0.624,0.681]$} \\
Hydro power (A5) & {$[0.042,0.063],[0.595,0.702],[0.525,0.583]$} \\
\hline
\end{tabular}

Applying TOPSIS method based on interval - valued neutrosophic numbers for the prioritization of alternatives in the next step, we will rank five alternatives to choose the best renewable energy sources. Then, the PIS and NIS of all alternatives under each subcriterion and the relative closeness coefficient of each alternative are determined as follows:

Table 5. PIS, NIS and the relative closeness coefficient of each alternatives.

\begin{tabular}{ccccc}
\hline Alternatives & D+ & D- & $\begin{array}{c}\text { Relative closeness } \\
\text { coefficient }\end{array}$ & Ranking \\
\hline Solar power (A1) & 0.753 & 0.368 & 0.672 & 2 \\
Wind power (A2) & 0.775 & 0.359 & 0.683 & 3 \\
Biomass power (A3) & 0.780 & 0.359 & 0.685 & 4 \\
Geothermal power (A4) & 0.790 & 0.356 & 0.690 & 5 \\
Hydro power (A5) & 0.737 & 0.375 & 0.662 & 1 \\
\hline
\end{tabular}

Finally, according to Table 5, the ranking of five alternatives is $A_{5} \succ A_{1} \succ A_{2} \succ A_{3} \succ A_{4}$. Thus, Hydropower is determined as the best energy source for Taiwan with the smallest relative closeness coefficient is 0.662 . This alternative is followed by Solar power, Wind power, Biomass power and Geothermal power, respectively. By the way, Geothermal power also is determined the worst alternative for Taiwan.

\section{Discussion and conclusion}

It is well accepted that renewable energy sources have advantages over conventional energy systems in terms of environmental acceptability. As a result, Taiwan government has set a target to contribute the development of renewable energy industry. The Ministry of Economic Affair (MOEA) estimated that the target of installed capacity of renewable energy would reach $12513 \mathrm{MW}$ by 2025 and further expand to $17250 \mathrm{MW}$ by 2030 [28]. So evaluating clean energy resources with many perspectives and criteria is a very important and difficult issue for government and investors.

In this paper, the model consisting of AHP and TOPSIS technique based on interval - valued neutrosophic sets is proposed to solve this problem. Through the advantages of combination of MCDM approach and interval - valued neutrosophic set, judgments from experts that have uncertain, ambiguous, indeterminate, inconsistent and incomplete information can be dealt better to evaluate energy decision making problems. 12 subcriteria that were identified from literature and expert's opinions were categorized into 4 groups (technical, economical, environmental, socio - political). All of jugdments from three experts have been taken as interval - valued neutrosophic numbers.

The results showed that the Hydropower is determined as the best energy source for Taiwan. Additionally, Solar power, Wind power and Biomass power are determined to be the second, third and fourth, respectively and followed by Geothermal power. Thus, investment priorities can be planned according to ranking in Table 5, Hydropower 
should be a priority in the development of renewable energy sources, both according to the abundance of energy supply and in accordance to geographical conditions.

In the future, similar studies can be conducted under an interval - valued neutrosophic environment with other MCDM techniques or sensitivity analysis will be performed to deal with more complex problems. The decision - making model under dynamic procedure as well will be proposed to advance the interval complex neutrosophic logic system for forecasting problems.

\section{Acknowledgements}

This study was financially supported by the Taiwan Building Technology Center from the Featured Areas Research Center Program within the framework of the Higher Education Sprout Project by the Ministry of Education in Taiwan under Project No. 107P011. It was also supported by the Department of Industrial Management of National Taiwan University of Science and Technology.

\section{References}

[1] H.-C. Lee and C.-T. Chang. Comparative analysis of MCDM methods for ranking renewable energy sources in Taiwan, Renewable and Sustainable Energy Reviews, 92 (2018) 883-96.

[2] A. Kumar, B. Sah, A.R. Singh, Y. Deng, X. He, P. Kumar, et al. A review of multi criteria decision making (MCDM) towards sustainable renewable energy development. Renewable and Sustainable Energy Reviews. 69 (2017) 596-609.

[3] N.T.A. Tuyet, Economic Feasibility Study for Supporting Renewable Energy Adoption. Thesis in Industrial Management. National Taiwan University of Science and Technology, 2018. p. 130.

[4] Y. Wu, C. Xu and T. Zhang. Evaluation of renewable power sources using a fuzzy MCDM based on cumulative prospect theory: A case in China. Energy. 147 (2018) 1227-39.

[5] T. Ertay, C. Kahraman and İ. Kaya. Evaluation of Renewable Energy Alternatives Using Macbeth and Fuzzy Ahp Multicriteria Methods: The Case of Turkey. Technological and Economic Development of Economy. 19 (2013) 38-62.

[6] M. Ali, L.Q. Dat, L.H. Son, F. Smarandache. Interval Complex Neutrosophic Set: Formulation and Applications in Decision-Making. International Journal of Fuzzy Systems. 20 (2017) 986-99.

[7] E. Bolturk and C. Kahraman. A novel interval-valued neutrosophic AHP with cosine similarity measure. Soft Computing. 22 (2018) 4941-58.

[8] J.-J. Peng, J.-Q. Wang, H.-Y. Zhang, X.-H. Chen. An outranking approach for multicriteria decision-making problems with simplified neutrosophic sets. Applied Soft Computing. 25 (2014) 336-46.

[9] P.L. Pingping Chi. An extended TOPSIS method for the multiple attribute decision making problems based on interval neutrosophic set. Neutrosophic Sets and Systems. 1 (2013), pp. 1-8.

[10] Z.-P. Tian, H.-Y. Zhang, J. Wang, J.-Q. Wang, X.-H. Chen. Multi-criteria decisionmaking method based on a cross-entropy with interval neutrosophic sets. International Journal of Systems Science. 47 (2015) 3598-608. 
[11] J. Ye. Similarity measures between interval neutrosophic sets and their applications in multicriteria decision-making, Journal of Intelligent \& Fuzzy Systems. 26 (2014) $165-72$.

[12] H.Y. Zhang, J.Q. Wang, X.H. Chen. Interval neutrosophic sets and their application in multicriteria decision making problems. ScientificWorldJournal. 2014 (2014) 645953.

[13] F. Smarandache. A unifying field in logics. neutrosophy: Neutrosophic probability, set and logic. American Research Press, Rehoboth, 1999.

[14] Y.-Y. Li, H. Zhang and J.-Q. Wang, Linguistic neutrosophic sets and their application in multicriteria decision-making problems. International Journal for Uncertainty Quantification. 7 (2017) 135 -54.

[15] M. Abdel-Basset, G. Manogaran, M. Mohamed, N. Chilamkurti. Three-way decisions based on neutrosophic sets and AHP-QFD framework for supplier selection problem. Future Generation Computer Systems. 89 (2018) 19-30.

[16] J.W. Ruxia Liang, H. Zhang. Evaluation of e-commerce websites: An integrated approach under a single-valued trapezoidal neutrosophic environment. KnowledgeBased Systems. 135 (2017) 44 -59.

[17] P. Ji, H.-Y. Zhang, J.-Q. Wang. Selecting an outsourcing provider based on the combined MABAC-ELECTRE method using single-valued neutrosophic linguistic sets. Computers \& Industrial Engineering. 120 (2018) 429-41.

[18] H. Wang, F. Smarandache, Y.-Q. Zhang, R. Sunderraman. Interval neutrosophic sets and logic: Theory and applications in computing, Hexis, Arizona, 2005.

[19] C. Kahraman, İ. Kaya. A fuzzy multicriteria methodology for selection among energy alternatives. Expert Systems with Applications. 37 (2010) 6270-81.

[20] A. Tasri, A. Susilawati. Selection among renewable energy alternatives based on a fuzzy analytic hierarchy process in Indonesia. Sustainable Energy Technologies and Assessments. 7 (2014) 34-44.

[21] T. Kaya, C. Kahraman. Multicriteria renewable energy planning using an integrated fuzzy VIKOR \& AHP methodology: The case of Istanbul. Energy. 35 (2010) 2517 27.

[22] T. Kaya, C. Kahraman. Multicriteria decision making in energy planning using a modified fuzzy TOPSIS methodology. Exp Syst with Appl., 38 (2011) 6577-85.

[23] J.R. San Cristóbal. Multi-criteria decision-making in the selection of a renewable energy project in spain: The Vikor method. Renewable Energy. 36 (2011) 498-502.

[24] A. Yazdani-Chamzini, M.M. Fouladgar, E.K. Zavadskas, S.H.H. Moini. Selecting the optimal renewable energy using multi criteria decision making. Journal of Business Economics and Management. 14 (2013) 957-78.

[25] M. Çolak, İ. Kaya. Prioritization of renewable energy alternatives by using an integrated fuzzy MCDM model: A real case application for Turkey. Renewable and Sustainable Energy Reviews. 80 (2017) 840-53.

[26] J. Ye. Multicriteria decision-making method using the correlation coefficient under single-valued neutrosophic environment. International Journal of General Systems. 42 (2013) $386-94$.

[27] M.B.S. Nouran M. Radwan, Alaa El Din M. Riad. Neutrosophic AHP Multi Criteria Decision Making Method Applied on the Selection of Learning Management System. Int. J. of Advancements in Computing Technology. 8 (2016) 95 -105.

[28] C.-T. Chang, H.-C. Lee. Taiwan's renewable energy strategy and energy-intensive industrial policy. Renewable and Sustainable Energy Reviews. 64 (2016) 456-65. 